\title{
Peripheral neuropathy in patients with $\beta$-thalassaemia
}

Dimitris A Papanastasiou, Dimitris Papanicolaou, Alexandra-Maria Magiakou, Nicholas G Beratis, Errikos Tzebelikos, Theodor Papapetropoulos
University of Patras Medical School, Regional University Hospital of Patras, Patras, Greece

Department of Pediatrics D A Papanastasiou A-M Magiakou N G Beratis

Department of Neurology D Papanicolaou E Tzebelikos T Papapetropoulos Correspondence to: Dr Papanastasiou, University of Patras Medical School, Regional University Hospital of Patras, PO Box 1045, 26500 Patras, Greece Received 12 February 1990 and in final revised form and in final revised

Accepted 28 February 1991

\begin{abstract}
As some patients with $\beta$-thalassaemia manifested neurological signs, clinical and electrophysiological investigations were carried out on 53 thalassaemic patients and 29 healthy control subjects. Twenty per cent of the patients showed clinical and electrophysiological findings of a mild peripheral sensorimotor neuropathy, mainly of the lower limbs. The clinical symptoms were numbness, pins and needles sensations, muscular cramps, myalgia and muscle weakness. The electrophysiological abnormalities were manifested by decreased motor conduction velocity (MCV) and prolonged $F$-wave latencies of the tibial and the peroneal nerves. Borderline increase in the latencies of the sensory potentials of the median nerve was also observed. The electromyographic findings of the patients with diminished MCVs were compatible with a predominantly motor peripheral neuropathy. This neuropathy appears during the second and third decade of life.
\end{abstract}

Numerous complications have been described in patients with $\beta$-thalassaemia, mainly due to chronic anaemia and haemosiderosis, which result in dysfunction of several organs and systems. ${ }^{1}$ There are very few studies referring to neuromuscular complications in such patients. This reflects the lack of any major damage of the nervous system and skeletal muscles at least during the first decade of life in thalassaemic patients, as a longer survival of these patients into adolescence and early adulthood is a recent achievement. A few cases of focal neurological episodes, ${ }^{23}$ as well as nerve deafness ${ }^{245}$ have been described in thalassaemic patients. Clinical and electromyographic findings of a myopathic syndrome have been reported by Logothetis et $a l^{2}$ Recently serious auditory and visual neurotoxic abnormalities have been identified in patients requiring chronic blood transfusions and undergoing deferoxamine iron chelation therapy. ${ }^{6}$

We report clinical and electrophysiological findings demonstrating an age related peripheral neuropathy in $\beta$-thalassaemic patients.
Material and methods

A total of 53 thalassaemic patients, treated during the past five years in the Thalassaemia Unit of the University of Patras Medical School, participated in the study. Patients were not selected according to clinical symptoms and treatment compliance. Sixteen of the 53 patients had $\beta$-thalassaemia intermedia, whereas the remainder $\beta$-thalassaemia major.

All patients were transfused with $10-15 \mathrm{ml}$ of washed red blood cells per kg of body weight at intervals of 15-30 days depending on the haematocrit value. Over the five year follow up period the mean (SD) haematocrit was 29.6 (1.9) before transfusion and 36.6 (3.3) after transfusion. During this period 49 out of the 53 patients were treated with subcutaneous infusions of deferoxamine. Although the recommended deferoxamine daily dose was 40 $50 \mathrm{mg} / \mathrm{Kg}$, five days per week, the patients' compliance was suboptimal. The mean (SD) deferoxamine dose per day they reported receiving was 26 (13) $\mathrm{mg} / \mathrm{Kg}$, for four to five days weekly. Ferritin was measured every six months. The mean blood ferritin value (SD) was $3714(2588) \mathrm{ng} / \mathrm{ml}$.

In all patients clinical examination and standard laboratory tests were performed at regular intervals. Blood glucose was measured monthly and glucose tolerance tests were performed every six months. Patients with abnormal glucose tolerance tests were excluded from the study. Twenty nine healthy control subjects participated in the study. The mean (SD) age of the patients and the control subjects were $17.9(7 \cdot 9)$ years and $17.3(9.6)$ years, respectively. The mean heights (SD) were $148.9(18.3) \mathrm{cm}$ and $158.6(19.7) \mathrm{cm}$, respectively.

A detailed neurological examination was performed on the patients and the control subjects by DP and ET.

The electrophysiological evaluation included standard motor conduction velocity (MCV) measurements of the deep peroneal (fibula head-ankles), tibial (popliteal fossaankles) and media (elbow-wrist) nerves. Surface electrode recordings were performed from the extensor digitorum brevis (EDB), the abductor hallucis (AH) and the abductor pollicis brevis (APB) muscles. Sural sensory action potentials were recorded antidromically, while median sensory nerve action potentials 
(index to wrist) orthodromically. F-waves were recorded from the same muscles with ankle or wrist stimulation and the shortest latencies were measured (shortest latency between the ankle or wrist-anterior horn-muscle distance to the motor fibres). Skin temperature of the tested limbs was measured with a temperature monitoring circuit through an external probe (Nicolet-Compact Four, EMG preamplifier) and was kept constant at $34^{\circ} \mathrm{C}$ with the help of an infrared lamp.

The electromyographic (EMG) studies were carried out in separate sessions, after the measurement of the conduction velocity, with the use of concentric needle electrodes for selected muscles (gastrocnemious, anterior tibialis, quadriceps femoris, gluteus maximus, biceps brachialis and deltoid). The twelve patients with the lowest MCV values were selected from the study group for EMG evaluation and eight of them agreed to the examination.

Statistical analysis was performed by using student's $t$ test and estimation of the slopes and covariances of the regressions.

\section{Results \\ NEUROLOGICAL EXAMINATION}

Among the 53 patients with $\beta$-thalassaemia there were eight patients who complained occasionally of numbness, pins and needles sensations, muscular cramps, mainly of the gastrocnemius muscle and myalgia referring to the lower extremities. In addition, there was one patient with all of the above symptoms except myalgia. Mild weakness in distal limb muscles (4.5 on the Medical Research Council scale, 1943) was found in 26 patients. Muscle atrophy was not present, whereas muscles were usually slender.

One or more of the deep tendon reflexes were reduced or abolished in 10 of the patients. The knee jerk was reduced in all ten of these and the biceps brachialis and ankle jerk in six. In three patients the ankle jerk was abolished. There

Table 1 Electrophysiological findings in $\beta$-thalassaemic patients and control subjects. Mean $(S D)$

\begin{tabular}{|c|c|c|c|}
\hline Nerves & Thalassaemic & Control & $T$-test \\
\hline $\begin{array}{l}\text { Motor conduction } \\
\text { Tibial nerve } \\
\text { Peroneal nerve } \\
\text { Median nerve }\end{array}$ & $\begin{array}{l}48.7(4 \cdot 1) \\
49 \cdot 1(3.4) \\
58.9(3.4)\end{array}$ & $\begin{array}{l}51 \cdot 6(3 \cdot 2) \\
52 \cdot 2(2 \cdot 7) \\
60 \cdot 0(3 \cdot 5)\end{array}$ & $\begin{array}{l}P<0.005 \\
P<0.005 \\
P>0.05\end{array}$ \\
\hline $\begin{array}{l}\text { Amplitude of com } \\
\text { Tibial nerve } \\
\text { Peroneal nerve } \\
\text { Median nerve }\end{array}$ & $\begin{array}{c}\text { potential in } m V \\
7 \cdot 0(2 \cdot 6) \\
4.5(2 \cdot 0) \\
9.7(3 \cdot 2)\end{array}$ & $\begin{array}{l}7 \cdot 4(3 \cdot 0) \\
4.8(1.5) \\
8.9(3 \cdot 1)\end{array}$ & $\begin{array}{l}P>0.1 \\
P>0.1 \\
P>0.1\end{array}$ \\
\hline $\begin{array}{l}\text { Duration of comp } \\
\text { Tibial nerve } \\
\text { Peroneal nerve } \\
\text { Median nerve }\end{array}$ & $\begin{array}{c}8.3(1.6) \\
10.4(2.0) \\
10.5(1.5)\end{array}$ & $\begin{array}{r}8.6(1.3) \\
9.7(1.5) \\
10.3(1.2)\end{array}$ & $\begin{array}{l}P>0.1 \\
P>0.05 \\
P>0.1\end{array}$ \\
\hline $\begin{array}{l}\text { Distal motor late } \\
\text { Tibial nerve } \\
\text { Peroneal nerve } \\
\text { Median nerve }\end{array}$ & $\begin{array}{l}3.6(0.7) \\
3.5(0.5) \\
2.7(0.4)\end{array}$ & $\begin{array}{l}3.7(0.7) \\
3.8(0.2) \\
2.9(0.6)\end{array}$ & $\begin{array}{l}P>0.1 \\
P>0.05 \\
P>0.1\end{array}$ \\
\hline $\begin{array}{l}\text { Sensory latency } \\
\text { Median nerve } \\
\text { Sural nerve }\end{array}$ & $\begin{array}{l}2.0(0.2) \\
2.6(0.4)\end{array}$ & $\begin{array}{l}1.9(0.2) \\
2.5(0.4)\end{array}$ & $\begin{array}{l}P<0.05 \\
P>0.1\end{array}$ \\
\hline $\begin{array}{l}\text { Sensory action p } \\
\text { Median nerve } \\
\text { Sural nerve }\end{array}$ & $\begin{array}{l}1.9(0.2) \\
1.7(0.3)\end{array}$ & $\begin{array}{l}1.9(0.2) \\
1.7(0.2)\end{array}$ & $\begin{array}{l}P>0.1 \\
P>0.1\end{array}$ \\
\hline $\begin{array}{l}\text { Sensory action } p \\
\text { Median nerve } \\
\text { Sural nerve }\end{array}$ & $\begin{array}{l}\mu V \\
27 \cdot 7(7 \cdot 9) \\
16 \cdot 2(6 \cdot 8)\end{array}$ & $\begin{array}{l}25.9(9.3) \\
18.1(5.8)\end{array}$ & $\begin{array}{l}P>0.1 \\
P>0.1\end{array}$ \\
\hline
\end{tabular}

was no evidence of cranial nerve involvement, pyramidal, extrapyramidal or cerebellar dysfunction or sensory loss.

\section{ELECTRONEUROGRAPHIC (ENG) ASSESSMENT}

The table lists the mean (SD) values of the $\mathrm{MCV}$, the amplitude, and the duration of the compound muscle action potentials and the distal latency for the tibial, peroneal and median nerves from the thalassaemic patients and the control subjects. The mean MCV values for the tibial and peroneal nerves were significantly lower in the patients than in the control population, whereas no significant difference was observed in the MCV values of the median nerve between the patients and the control subjects. Among the thalassaemic patients there were nine $(16.9 \%)$ and 11 patients $(20.7 \%)$, who demonstrated abnormally diminished MCV values (2SD below the mean control value) for the tibial and peroneal nerves, respectively. Six of them had abnormally low values for both nerves. MCV values between $-1 S D$ and $-2 S D$ from the mean control value showed 17 patients $(38.6 \%)$ for the tibial nerve and 12 patients $(28.6 \%)$ for the peroneal nerve, whereas only five control subjects $(17 \cdot 2 \%)$ demonstrated MCVs within this range of values. The remainder of the patients presented MCVs for both the tibial and the peroneal nerves which were near the mean value of the control group or at the upper normal limits. No statistically significant difference between patients and control subjects was observed for the amplitude and duration of the compound muscle action potentials and distal latency.

In the table we have also tabulated the latency, duration and amplitude of the sensory potentials of the median and sural nerves obtained from the patients and the control subjects. A significant increase in the latencies of the median nerve was observed in the thalassaemic patients, whereas no statistically significant difference between patients and control subjects was found in the other parameters measured (table).

The shortest $\mathrm{F}$-wave latencies for the peroneal (EDB muscle), the tibial (AH muscle) and the median (APB muscle) nerves in the patients and the control subjects were adjusted for a mean height of $152 \mathrm{~cm}$, that is the mean value of the heights of the patients and the control subjects. The mean (SD) values of the shortest F-wave latencies for the tibial nerve of the patients was $42.92(3.20) \mathrm{ms}$, with a range from $35.40 \mathrm{~ms}$ to $51.31 \mathrm{~ms}$, whereas in the control subjects it was $41 \cdot 49(3 \cdot 17) \mathrm{ms}$ with a range from $33.39 \mathrm{~ms}$ to $46.90 \mathrm{~ms}(t=1.938$, $\dot{p} \leq 0.05)$. For the peroneal nerve the mean (SD) value in the patients was $41.38(3.29) \mathrm{ms}$, with a range from $31.23 \mathrm{~ms}$ to $46.55 \mathrm{~ms}$, whereas in the control group it was $39.64(3.07)$ $\mathrm{ms}$, with a range from $32.31 \mathrm{~ms}$ to $45.60 \mathrm{~ms}$ $(\mathrm{t}=2.346, \quad \mathrm{p} \leq 0.025)$. However, no significant difference was observed for the median nerve between the patients and the control subjects; patients: $23.60(1.45) \mathrm{ms}$, range from $21.09 \mathrm{~ms}$ to $27.28 \mathrm{~ms}$, control subjects: $23.54(1.59) \mathrm{ms}$, range from $20.73 \mathrm{~ms}$ to $28.44 \mathrm{~ms}(\mathrm{t}=0.187, \mathrm{p} \geqslant 0.4)$. 
EMG ASSESSMENT

The EMG examination of the anterior tibialis and the gastrocnemious muscles showed a neuropathic volitional contraction pattern in six of the eight thalassaemic patients studied. Also, in three of these patients a number of polyphasic motor unit potentials, with prolonged durations of the reinnervation type, were observed, whereas in two patients fibrillation potentials were recorded indicating denervation. The quadriceps femoris demonstrated a volitional contraction pattern near to the lower normal limits, without any other specific neuropathic character. The gluteus maximus, the biceps brachialis and the deltoid muscles had EMG patterns within the normal limits.

\section{ANALYSIS OF ENG FINDINGS}

The ENG findings of the thalassaemic patients were analysed for age, the mean blood volume transfused $/ \mathrm{kg} /$ year, the mean haematocrit value for the last five years, the deferoxamine dose infused and the serum ferritin values. Also, the severity of the disease (intermedia or major) and the performance or not of splenectomy were considered. There was a negative correlation between the magnitude of the MCV values of the tibial and the peroneal nerves and the age in the group of the thalassaemic patients, whereas no such correlation was found in the control subjects. The t-values for the covariances of the regression lines are highly significant (tibial nerve: $t$-value for covariance $3.82, p<0.005$; peroneal nerve: $\mathrm{t}$-value for covariance $4.65, \mathrm{p}<0.005$ ). On the other hand, the MCVs of the median nerve were not affected by the age of the patients ( $\mathrm{t}$-value for covariance $1.41,0 \cdot 10<\mathrm{p}<0.05$ ).

Also there was a statistically significant negative correlation between the diminished MCV values of the tibial and peroneal nerves and the mean haematocrit value during the last five years ( $p<0.005$ for both nerves).

Conversely, there was no significant correlation between the MCV values of the nerves studied and the ferritin levels, as well as between the MCVs and the deferoxamine dose administered to the patients. There was also no correlation between MCV values and those patients who had or had not had a splenectomy.

Diminished MCV values were observed in patients with both the intermedia and the major type of the disease; both groups were equally affected.

\section{Discussion}

Clinical, as well as ENG and EMG data lead to the conclusion that $22 \%$ of the patients with $\beta$-thalassaemia treated in our unit developed a mild peripheral neuropathy, mainly motor, during the second decade of life. The electrophysiological findings in these patients correlated well with a mild distal limb muscular weakness and sensory complaints.

The literature on the function of the peripheral nerves in patients with $\beta$-thalassaemia is very limited. McIntosh, ${ }^{4}$ Hazell ${ }^{5}$ and Logothetis $e t a l^{2}$ have reported a few patients who developed nerve deafness in the course of the disease. Recently, neurotoxicity due to high doses of deferoxamine has been observed in patients with $\beta$-thalassaemia or BlackfanDiamond anaemia. ${ }^{6} \mathrm{~A}$ daily dose lower than 50 $\mathrm{mg} / \mathrm{kg}$ was considered safe. The mean deferoxamine dose taken by our patients was $26 \mathrm{mg} / \mathrm{kg}$, with a range from 0 to $53 \mathrm{mg} / \mathrm{kg}$. Analysis of the data failed to demonstrate a correlation between the MCVs of the peripheral nerves and the deferoxamine dose administered to the patients. This is in agreement with the observed lack of correlation between the MCVs of the peripheral nerves and the serum ferritin levels. The normal blood glucose and glucose tolerance tests obtained in the cases studied excluded the possibility that diabetes, a well known complication of thalassaemia during the second decade of life, was responsible for the peripheral neuropathy.

Logothetis et al have described a myopathic syndrome with proximal weakness, mainly in the lower limbs, accompanied by a myopathic electromyographic pattern. This observation is different from our EMG findings. However, $\beta$-thalassaemic patients studied by Logothetis et al were much younger and were treated quite differently from our patients, since they were transfused at long intervals (every 20-90 days), their mean pretransfusional haematocrit was very low $(23.8 \%)$ and had no iron chelation therapy.

The significant correlation between the decrease of the MCV values of the tibial and the peroneal nerves and the age of the patients may help to understand the pathogenic mechanism of the peripheral nerve damage. Thirteen out of the fourteen patients with the lowest MCVs were older than 15 years. This observation suggests that the factor(s) affecting the peripheral nerves might have acted over a long period of time causing a peripheral neuropathy in the older patients. However, the nerve lesion might have resulted from the poor treatment these patients had in the past, before our Thalassaemia Unit was developed. Factors which could be related to the peripheral neuropathy were analysed. A significantly positive correlation was observed between the MCVs of the tibial and peroneal nerves and the mean haematocrit value. McIntosh ${ }^{4}$ described an improvement in the hearing of a young thalassaemic patient, who had been maintained without blood transfusions, after starting regular blood transfusions. $\mathrm{He}$ also states that deafness is relatively common in young thalassaemics, particularly when inadequately transfused. Similar observations have been reported by Hazell and Modell. ${ }^{5}$ Our patients however, never reached very low haemoglobin values, at least during the last five years.

Interestingly, there was no difference in the frequency of peripheral neuropathy between the patients with thalassaemia intermedia and thalassaemia major. It should be mentioned that patients with thalassaemia intermedia, a condition associated with many distressing clinical complications, ${ }^{17-9}$ were maintained in the past without regular blood transfusions and had therefore low haematocrit levels during the 
course of the disease.

We conclude that patients with $\beta$-thalassaemia develop a predominantly motor peripheral neuropathy with increasing age. Mild chronic anaemia could be the factor or one of the factors leading to the peripheral nerve injury. However, the exact cause remains unclear.

1 Weatherall DJ, Clegg JB. The Thalassaemia syndromes, 3rd ed. Oxford: Blackwell, 1981 .

2 Logothetis J, Constantoulakis $\mathrm{M}$, Economidou $\mathrm{J}$, et al. Thalassaemia major (homozygous beta-thalassaemia). A survey of 138 cases with emphasis on neurologic and muscular aspects. Neurology 1972;22:294-304.

3 Sinniah D, Vignaendra V, Kamaruddin A. Neurological complications of $\beta$-thalassaemia major. Arch Dis Child 1977;52:977-9.

$4 \mathrm{McIntosh} N$. Beneficial effects of transfusing a patient with nontransfusion dependent thalassaemia major. Arch Dis Child 1976;51:471-2.

5 Hazell JW, Modell CB. ENT complications in thalassemia major. J Laryngol Otol 1976;90:877-82.

6 Olivieri NF, Buncic JR, Chew E, et al. Visual and auditory neurotoxicity in patients receiving subcutaneous deferoxamine infusions. $N$ Engl J Med 1986;314:869-73.

7 Bannerman R, Keusch G, Kreimer-Birnbaum M, Vance VK, Vaughan $S$. Thalassemia intermedia with iron overload, cardiac failure, diabetes mellitus, hypopituitarism and porphyrinuria. Am J Med 1967;42:476-86.

8 Erlandsson ME, Brilliant $\mathrm{R}$, Smith $\mathrm{CH}$. Comparison of sixty-six patients with thalassemia major and thirteen
six patients with thalassemia intermedia including evaluations of growth, development, maturation and prognosis. Ann NY Acad Sci 1964;119:721-35.

9 Pippard MJ, Callender ST, Warner GT, Weatherall DJ. Iron absorption and loading in thalassemia intermedia. Lancet 1979;ii:819-21. 